\title{
Landmark-based morphometric and meristic analysis in response to characterize the wild Bhagna, Labeo ariza populations for its conservation
}

\author{
A. K. Shakur Ahammad, Md. Borhan Uddin Ahmed, Salma Akhter and Md. Kamal Hossain
}

Department of Fisheries Biology \& Genetics, Bangladesh Agricultural University, Mymensingh-2202, Bangladesh

\section{ARTICLE INFO}

Article history:

Received: 26 December 2017

Accepted: 04 April 2018

Keywords:

Landmark based morphometry,

Labeo ariza, River, Body Shape

Variation

Correspondence:

A. K. Shakur Ahammad

(sahammad09@yahoo.com)

\begin{abstract}
The landmark-based morphometric and meristic analysis of three different stocks from the Atrai, the Jamuna and the Kangsha of Bhagna (Labeo ariza, Hamilton 1807) were examined from a phenotypical point of view to evaluate the population structure and to assess shape variation. A total of 90 Bhagna ( $L$. ariza) were collected from three different water bodies: the Atrai, the Jamuna and the Kangsha of Bangladesh during January, 2017. Ten morphometric and nine meristic characters were analyzed along with twenty two truss network measurements. One way ANOVA showed that all morphometric, meristic and truss network measurement were significantly different $(\mathrm{P}<0.001)$ among three different stock of the fish. For morphometric and landmark measurements, the first discriminant functions (DF) accounted for $98.6 \%$ and $97.9 \%$ and the second DF accounted for $1.4 \%$ and $2.1 \%$, respectively among group variability, explaining $100 \%$ of total among groups variability. For the morphometric and truss network measurements, plotting discriminant functions showed a well separated clusters of the stocks indicating that the measurement were significantly different among three stocks. The dendrogram based on morphometric and landmark distances data showed two major clusters; the Atrai and Jamuna stocks in one cluster and the Kangsha stock in another cluster. High degree of variation was observed in morphological characteristics among three different stocks (the Atrai, Jamuna and Kangsha) of $L$.ariza due to their environmental variation and separate geographical location. The results of this study are very useful for proper conservation and successful management of $L$. ariza and also for the scientific community for the further research.
\end{abstract}

\section{Introduction}

Bhagna (Labeo ariza) is considered as one of the most important small indigenous species (sis) in Bangladesh. This fish is easily recognizable by its medium sized silvery scales, deep bluish or darkish upper body part and the shiny and silvery lower body part. The lateral line has 38 or 39 scales, most of them appearing as a black mark elongated from the base margin of the operculum to the tail during the early stage of life (Rahman et al.,2009) while in the adult stage this black mark becomes shorter and remains between the operculum to the end of the belly. (Talwar and Jhingran, 1991; Hussain and Mazid, 2001; Rahman, 2005). This fish is distributed over Indo-pacific region (Jhingran, 1991; Walter, 1994; Rahman, 2005;Hogan, 2012). It inhabits clear rivers and tanks (Naser, 2015).In Bangladesh it is widely distributed in the Karnafuly River and adjacent basins in Chittagong hill tracts (Hogan, 2012; Roberts, 1997; Kohinoor et al.,1998). Naturally this fish is also distributed in most of the small rivers, floodplains, creeks natural depressions of Bangladesh (Hussain and Mazid, 2001; Felts et al., 1996). The fish is a plankton and detritus feeder. This fish additionally grows up to $30.0 \mathrm{~cm}$ in standard length and weight of 1,360 g. Females and males becomes sexually mature within one year and customarily by the terminus of first year. (Ahammad et al., 2015). On the other hand, in their studies they showed that Bhagna fish is a water column feeder and omnivore in nature and grows to a maximum size of 40 to $50 \mathrm{~cm}$ in total length (Rahman, 2005; Felts et al., 1996; Akhteruzzaman et al., 1998). Breeding takes place in flooded shallows in June-September (Roberts, 1997). Male is smaller than female (Talwar and Jhingran 1991). But according to Akhteruzzaman et al., (1998) and Hussainand Mazid (2001), the spawning season of Bhagna starts in April and ends in August with peak spawning occurring during the rainy seasons in flowing flood waters.

During the last few decades, the population of Bhagna has declined considerably due to increased fishing pressure and various anthropogenic activities leading to siltation, aquatic pollution, and loss of natural habitat for spawning and growth of this species. (Akhteruzzaman et al., 1998; Hussain and Mazid, 2001). Recently this species has been listed in IUCN red list (Dahanukar, 2010). So this species needs to be conserve in natural water body. Appropriate management strategy should be established to make it secure in nature as it is a highly popular fish to the consumers due to its oily flesh and taste qualities. Information on the biology and population structure of any species is a prerequisite for developing management and conservation strategies (Turan et. al., 2006). From the previous study it can be easily said that to depicture stocks of a particular fish, the analysis of phenotypic variation in morphometric or 
meristic characters is the most commonly used method (Creech, 1992; Mamuris et al., 1998; Bronte et al., 1999; Hockaday et al., 2000). Recognition of morphometric differences among stocks of a species are very important for evaluating the population structure of that species and as a basis for identifying stocks (Vishalakshi and Singh, 2008). Morphometric and meristic characters of fish are the measurable and countable characters, respectively common to all fishes (Rahman et al., 2014). Landmarks may define as some arbitrarily points which is selected on a fish's body and with the help of these arbitrarily points, the individual fish body shape can be analyzed. Truss network systems which is constructed with the help of this landmark points are powerful tools for stock identification. A sufficient degree of isolation may result in notable morphological, meristic and shape differentiation among different stocks of a species which may be a basis for identifying the stocks. Therefore, it is indispensable to know the morphological and meristic variations among the Atrai river, Jamuna river and Kangsha river as a preliminary base line information. There is possibly no previous information regarding the phenotypical variations of the Atrai, Jamuna and Kangsha river source of $L$. ariza and there is a few attempts by the scientific community to investigate the population structure of $L$. ariza based on genetic aspects. The present research work has therefore been undertaken to know the population structure of $L$. ariza from a phenotypical point of view to determine the morphometrics among three river stocks named the Atrai, Jamuna and Kangsha.

\section{Materials and Methods}

\section{Sample collection and measurement}

During January, 2017, a total of 90 Bhagna, L. ariza were collected live in oxygenated polythene bags from the Atrai, Jamuna and Kangsha river (30 species from each river) and kept temporarily in three separate cement tank at the wet laboratory complex, adjacent to the Faculty of Fisheries, Bangladesh Agricultural University, Mymensingh-2202, Bangladesh. The fishes were measured as $15.20-21.90 \mathrm{~cm}$ in total length (TL) by a measuring scale and 73-114 $\mathrm{g}$ in weight by a sensitive portable electric balance (AND, Japan). Mean length, mean weight and sample size of each sample were shown in table 01. Before starting the measurement fishes were handled with the help of a small piece of cloth and water was sucked finely by blotting paper from the fish body surface. For collecting morphometric data, "Truss network system" was used. Data points were arranged in "trusses" around the fish, a layout which maximizes the number of measurements and increases the sensitivity of the analysis were shown in Fig. 02.

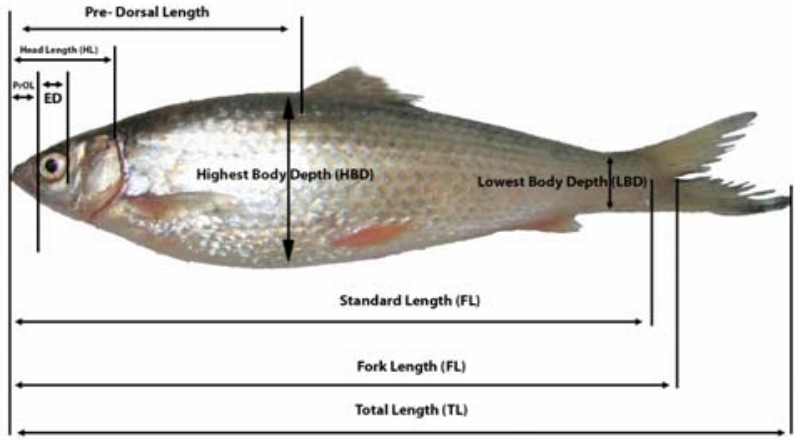

Fig 01: Morphometric measurements of L. ariza

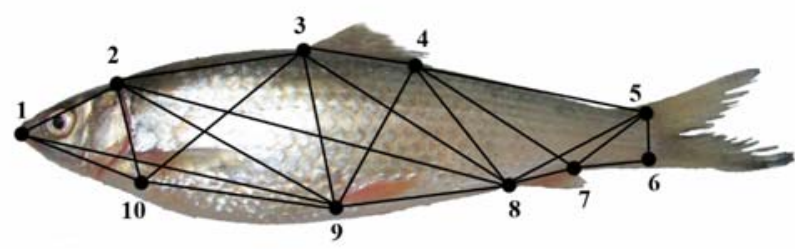

Fig 02: Locations of the 10 landmarks for constructing the truss network on $L$. ariza illustrated as black dots and morphometric distance measures between the dots as lines. Landmarks refer to (1) anterior tip of snout at upper jaw, (2) most posterior aspect of neuro cranium (beginning of scaled nape), (3) origin of dorsal fin, (4) insertion of dorsal fin, (5) anterior attachment of dorsal membrane from caudal fin, (6) anterior attachment of ventral membrane from caudal fin, (7) insertion of anal fin, (8) origin of anal fin, (9) insertion of pelvic fin and (10) insertion of pectoral fin.

A total of 9 meristic characters: dorsal fin rays (DFR), pectoral fin rays (PCFR), pelvic fin rays (PVFR), anal fin rays (AFR), caudal fin rays (CFR), branchiostegal rays (BSR), scale above lateral line (SaLL), sacale on lateral line, (SabLL) and scale below lateral line (SbLL) were analyzed. All the meristic counts were set up against incoming light direction in the room with the help of needle and small pins for easy counting. Ten landmarks delineating 22 distances were measured on the fish body (Fig. 02). Each landmark was obtained by placing a fish on graph paper and then the landmarks were detected with colored pointers for enabling accurate and consistent measurements. Finally, the distances on the graph paper were measured using centimeter scale.

Table 01. Average length $(\mathrm{cm})$ and weight $(\mathrm{g})$ of the samples collected from different sources

\begin{tabular}{lccc}
\hline Group Name & $\begin{array}{c}\text { Sample } \\
\text { size }\end{array}$ & $\begin{array}{c}\text { Total Length } \\
(\mathrm{M} \pm \mathrm{SD})\end{array}$ & $\begin{array}{c}\text { Weight } \\
(\mathrm{M} \pm \mathrm{SD})\end{array}$ \\
\hline Atrai River & 30 & $21.11 \pm 0.39$ & $106.14 \pm 0.56$ \\
Jamuna River & 30 & $17.81 \pm 0.59$ & $86.36 \pm 1.29$ \\
Kangsha River & 30 & $15.92 \pm 0.48$ & $78.43 \pm 0.31$ \\
\hline Total & 90 & $18.28 \pm 2.21$ & $90.31 \pm 3.08$ \\
\hline
\end{tabular}

\section{Statistical analyses}

Prior to analysis, the size effects from the data set were eliminated to ensure that the variations were only attributed to body shape differences and not to the relative sizes of the fish. In the present study, there were significant linear correlations among all the measured 
characters and the total length (TL) of the fish. Therefore, it was necessary to remove size-dependent variations from all of the measured morphometric characters. An allometric formula given by Elliott et. al., (1995) with slight modification was used to remove the size effect from the data set. The formula is as following

$\mathrm{M}_{\mathrm{adj}}=\mathrm{M}\left(\mathrm{L}_{\mathrm{s}} / \mathrm{L}_{\mathrm{o}}\right)^{\mathrm{b}}$

Where $\mathrm{M}$ is the original measurement, $\mathrm{M}_{\mathrm{adj}}$ is the sizeadjusted measurement, $L_{o}$ is the TL of the fish and $L_{s}$ is the overall mean of the TL for all fish from all samples. Parameter b was calculated for each character from the observed data as the slope of the regression of $\log \mathrm{M}$ on $\log \mathrm{L}_{0}$, using all fish in all stocks. The efficiency of the size adjustment transformations was assessed by testing the significance of the correlation between a transformed variable and the TL. A univariate analysis of variance (ANOVA) was carried out to test the significance of morphological differences. Meristic characters were compared between stocks using the nonparametric Kruskal-Wallis test. In addition, sizeadjusted data were standardized and submitted to a discriminant function (DF) analysis. A dendrogram of the populations based on the morphometric and landmark distance data was drawn using the "Squared Euclidean dissimilarity distance" method. SPSS software package version 21 was used for all the statistical analysis in this experiment.

\section{Results}

\section{Meristic Counts}

Nine Meristic counts with their median values for all samples were shown in Table 2. Among the correlation measurements, DFR was correlated with CFR with significant difference $(\mathrm{P}<0.05)$ and highly correlated with SaLL, SabLL and SbLL $(\mathrm{P}<0.01)$. CFR was correlated with SabLL $(\mathrm{P}<0.05)$. There were no significant differences among mean number of PCFR, PVFR, AFR, BSR and differences were occurred only in other characters ( One way ANOVA test showed $\mathrm{DF}=2$ for all three samples where DFR: $\mathrm{F}_{\mathrm{st}}=261, \mathrm{P}<0.05$; PCFR: $\mathrm{F}_{\mathrm{st}}=88.182, \mathrm{P}<0.05$ and PVFR: $\mathrm{F}_{\mathrm{st}}=1, \mathrm{P}>0.05$ ); CFR: $\mathrm{F}_{\mathrm{st}}=3.415, \mathrm{P}<0.05$; BSR: $\mathrm{F}_{\mathrm{st}}=1.024, \mathrm{P}>0.05$; SaLL: $\mathrm{F}_{\mathrm{st}}=853.317, \quad \mathrm{P}<0.05 ;$ SabLL: $\mathrm{F}_{\mathrm{st}}=694.665, \quad \mathrm{P}<0.05$; SbLL: $\mathrm{F}_{\mathrm{st}}=11.429, \mathrm{P}<0.05$; In the Kruskal-Wallis $(\mathrm{H})$ test, similar results were found. $\mathrm{P}>0.05$ and $\mathrm{DF}=2$ found for PVFR, AFR and BSR. And for other characters $\mathrm{P}<0.05$ and $\mathrm{DF}=2$ was found in KruskalWallis $(\mathrm{H})$ test.

\section{Morphometric and landmark distances}

The efficiency of the allometric formula in removing the size effect from the data was justified by using correlations between the total length and adjusted characters. Among the 10 transformed morphometric and 22 truss measurements, none of them were found to be significantly correlated $(\mathrm{P}>0.05)$. Therefore, all the measurements were considered for further calculation. A univariate statistical analysis (ANOVA) of ten morphometric characters and twenty two landmark distances showed that all morphometric measurements and truss measurements were highly different among samples $(\mathrm{P}<0.001)$ (Table 3 and Table 4$)$, respectively.

Table 02. Meristic counts (median) of Bhagna ( $L$. ariza) of three different stocks (in the parenthesis indicates minimum and maximum counts)

\begin{tabular}{cccc}
\hline Characters & Atrai River & Jamuna River & Kongsha River \\
\hline DFR & $9(9-10)$ & $10(10-10)$ & $10(10-10)$ \\
PCFR & $28(28-30)$ & $30(30-32)$ & $26(22-30)$ \\
PVFR & $18(18-18)$ & $18(18-18)$ & $18(18-20)$ \\
AFR & $7(7-7)$ & $7(7-7)$ & $7(7-7)$ \\
CFR & $25(21-29)$ & $26.5(22-31)$ & $24(20-34)$ \\
BSR & $8(6-8)$ & $8(8-8)$ & $8(6-8)$ \\
SaLL & $377(296-490)$ & $79(71-92)$ & $80(70-86)$ \\
SabLL & $88(76-104)$ & $447(306-533)$ & $401(284-540)$ \\
SbLL & $630(412-796)$ & $553.5(406-664)$ & $550(448-684)$ \\
\hline
\end{tabular}

Table 03. Univariate statistics (ANOVA) of all ten morphometric measurements in three samples

\begin{tabular}{cccccc}
\hline Character & $\begin{array}{c}\text { Wilks' } \\
\text { Lambda }\end{array}$ & $\mathrm{F}$ & $\mathrm{df}_{1}$ & $\mathrm{df}_{2}$ & Sig. \\
\hline TL & .054 & 764.369 & 2 & 87 & $.000^{*}$ \\
FL & .073 & 549.045 & 2 & 87 & $.000^{*}$ \\
SL & .078 & 513.687 & 2 & 87 & $.000^{*}$ \\
HL & .089 & 445.575 & 2 & 87 & $.000^{*}$ \\
ED & .096 & 408.625 & 2 & 87 & $.000^{*}$ \\
HBD & .066 & 614.488 & 2 & 87 & $.000^{*}$ \\
LBD & .040 & 1031.383 & 2 & 87 & $.000^{*}$ \\
PrOL & .094 & 417.269 & 2 & 87 & $.000^{*}$ \\
PDL & .058 & 709.294 & 2 & 87 & $.000^{*}$ \\
MG & .061 & 672.422 & 2 & 87 & $.000^{*}$ \\
\hline
\end{tabular}

$(*) \mathrm{p}<0.001$

Table 04. Univariate statistics (ANOVA) of all twenty two truss measurements in three samples

\begin{tabular}{cccccc}
\hline Distance & $\begin{array}{c}\text { Wilks' } \\
\text { Lambda }\end{array}$ & $\mathrm{F}$ & $\mathrm{df}_{1}$ & $\mathrm{df}_{2}$ & Sig. \\
\hline dist 1-2 & .169 & 213.248 & 2 & 87 & $.000^{*}$ \\
dist 2-3 & .149 & 248.125 & 2 & 87 & $.000^{*}$ \\
dist 3-4 & .127 & 299.945 & 2 & 87 & $.000^{*}$ \\
dist 4-5 & .068 & 593.756 & 2 & 87 & $.000^{*}$ \\
dist 5-6 & .025 & 1691.398 & 2 & 87 & $.000^{*}$ \\
dist 6-7 & .098 & 399.127 & 2 & 87 & $.000^{*}$ \\
dist 7-8 & .045 & 918.817 & 2 & 87 & $.000^{*}$ \\
dist 8-9 & .027 & 1549.699 & 2 & 87 & $.000^{*}$ \\
dist 9-10 & .197 & 177.287 & 2 & 87 & $.000^{*}$ \\
dist 1-10 & .056 & 736.440 & 2 & 87 & $.000^{*}$ \\
dist 2-10 & .045 & 926.906 & 2 & 87 & $.000^{*}$ \\
dist 3-10 & .086 & 461.506 & 2 & 87 & $.000^{*}$ \\
dist 1-9 & .069 & 589.036 & 2 & 87 & $.000^{*}$ \\
dist 2-9 & .108 & 359.792 & 2 & 87 & $.000^{*}$ \\
dist 3-9 & .156 & 235.570 & 2 & 87 & $.000^{*}$ \\
dist 4-9 & .128 & 295.747 & 2 & 87 & $.000^{*}$ \\
dist 2-8 & .108 & 357.479 & 2 & 87 & $.000^{*}$ \\
dist 3-8 & .055 & 745.253 & 2 & 87 & $.000^{*}$ \\
dist 4-8 & .092 & 431.884 & 2 & 87 & $.000^{*}$ \\
dist 5-8 & .060 & 676.253 & 2 & 87 & $.000^{*}$ \\
dist 4-7 & .126 & 300.768 & 2 & 87 & $.000^{*}$ \\
dist 5-7 & .114 & 337.112 & 2 & 87 & $.000^{*}$ \\
\hline (*) P 0.001 & & & & &
\end{tabular}

$\left({ }^{*}\right) \mathrm{p}<0.001$ 
Discriminant function analysis produced two discriminant functions $\left(\mathrm{DF}_{1}\right.$ and $\left.\mathrm{DF}_{2}\right)$ for both morphometric and landmark measurements. For morphometric and landmark measurements the first DF accounted for $98.6 \%$ and $97.9 \%$ and the second DF accounted for $1.4 \%$ and $2.1 \%$, respectively of among group variability and mutually they explained $100 \%$ of the total among groups variability. All stocks were morphometrically different and clearly separated from each other in the discriminant space (Fig. 03, canonical graph) and virtually no overlapping. The canonical graph of Atrai River (Stock 1), then the Jamuna River (Stock 2) and finally the Kangsha River (Stock 3) were sequentially distributed in cluster form around their centroid values. In case of all truss measurements, three stocks were also differed from each other in the discriminant space. (Fig. 04. canonical graph).This finding suggested that there was no intermixing among populations and the populations were fully separated.

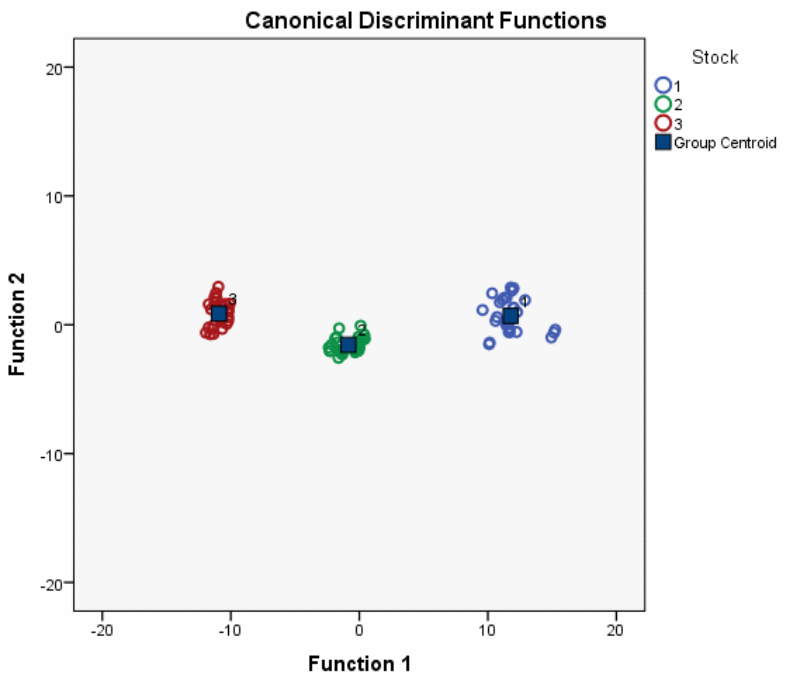

Fig. 03. Sample centroids of discriminant function scores based on morphometric measurements. Samples referred to, 1. Atrai River, 2.Jamuna River, 3.Kangsha River

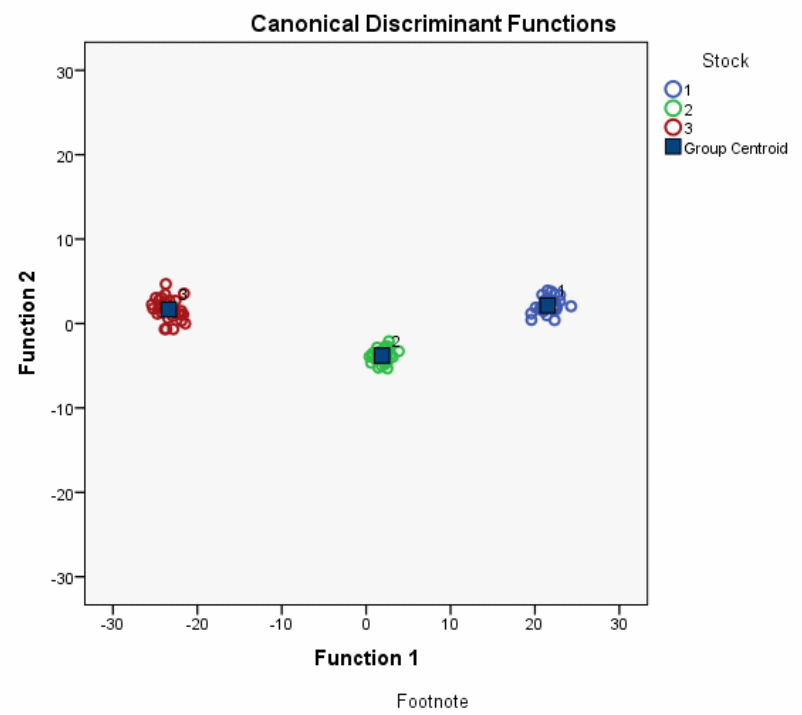

Fig. 04. Sample centroids of discriminant function scores based on truss measurements. Samples referred to, 1. Atrai River, 2.Jamuna River, 3.Kangsha River
Pooled within group correlations between discriminant variables and DFs revealed that among ten morphometric measurements: eight measurements of lowest body depth (LBD), total length (TL), predorsal length (PDL), mouth gap (MG), highest body depth (HBD), fork length (FL) standard length (SL) and head length (HL) dominantly contributed to the first DF and the rest two characters: eye diameter (ED) and preorbital length (PrOL) contributed to the second DF (Table 5). Among twenty two truss measurements; sixteen measurements of dist 8-9, dist 7-8, dist 3-8, dist $1-9$, dist 3-10, dist 4-8, dist 6-7, dist 2-9, dist 2-8, dist 57 , dist $4-7$, dist 3-4, dist 4-9, dist 3-9, dist $1-2$, dist 9-10 dominantly contributed to the first DF and the rest six contributed to the second DF (Table 6).

Table 05. Pooled within-groups correlations between discriminating variables and standardized canonical discriminant functions (Variables ordered by absolute size of correlation within function). (*) denotes the largest absolute correlation between each variable and any discriminant function

\begin{tabular}{ccc}
\hline Character & $\mathrm{DF}_{1}$ & $\mathrm{DF}_{2}$ \\
\hline LBD & $0.513\left(^{*}\right)$ & -0.404 \\
TL & $0.443\left(^{*}\right)$ & 0.200 \\
PDL & $0.427\left(^{*}\right)$ & 0.179 \\
MG & $0.414\left(^{*}\right)$ & -0.383 \\
HBD & $0.397\left(^{*}\right)$ & -0.206 \\
FL & $0.376\left(^{*}\right)$ & 0.118 \\
SL & $0.363\left(^{*}\right)$ & 0.158 \\
HL & $0.338\left(^{*}\right)$ & -0.162 \\
ED & 0.322 & $-0.349\left(^{*}\right)$ \\
PrOL & 0.326 & $-0.328\left(^{*}\right)$ \\
\hline
\end{tabular}

Table 06. Pooled within-groups correlations between discriminating variables and standardized canonical discriminant functions (Variables ordered by absolute size of correlation within function). (*) denotes the largest absolute correlation between each variable and any discriminant function

\begin{tabular}{ccc}
\hline Distance & $\mathrm{DF}_{1}$ & $\mathrm{DF}_{2}$ \\
\hline dist $8-9$ & $0.319\left(^{*}\right)$ & 0.071 \\
dist 7-8 & $0.245\left(^{*}\right)$ & -0.110 \\
dist 3-8 & $0.220\left(^{*}\right)$ & 0.152 \\
dist 1-9 & $0.197\left(^{*}\right)$ & 0.013 \\
dist 3-10 & $0.173\left(^{*}\right)$ & -0.168 \\
dist 4-8 & $0.167\left(^{*}\right)$ & 0.140 \\
dist 6-7 & $0.162\left(^{*}\right)$ & -0.036 \\
dist 2-9 & $0.154\left(^{*}\right)$ & -0.071 \\
dist 2-8 & $0.153\left(^{*}\right)$ & 0.043 \\
dist 5-7 & $0.149\left(^{*}\right)$ & -0.057 \\
dist 4-7 & $0.141\left(^{*}\right)$ & 0.047 \\
dist 3-4 & $0.141\left(^{*}\right)$ & -0.006 \\
dist 4-9 & $0.139\left(^{*}\right)$ & 0.088 \\
dist 3-9 & $0.124\left(^{*}\right)$ & -0.020 \\
dist $1-2$ & $0.118\left(^{*}\right)$ & -0.068 \\
dist 9-10 & $0.108\left(^{*}\right)$ & 0.035 \\
dist 5-6 & 0.325 & $-0.513(*)$ \\
dist 1-10 & 0.214 & $-0.359\left(^{*}\right)$ \\
dist 5-8 & 0.207 & $0.293\left(^{*}\right)$ \\
dist 4-5 & 0.193 & $0.289\left(^{*}\right)$ \\
dist 2-10 & 0.244 & $-0.259\left(^{*}\right)$ \\
dist 2-3 & 0.124 & $0.206\left(^{*}\right)$ \\
\hline
\end{tabular}


A dendrogram (Fig. 05) based on morphometric and landmark distance data was drawn for the stocks of the Atrai River, Jamuna River and Kangsha River. The Atrai River and the Jamuna River population formed one cluster. On the other hand Kangsha population formed separated cluster based on the distance of squared euclidean dissimilarity method which demonstrated that distance was close among the Atrai River and Jamuna River stocks and the distance for Kangsha River stock was more deviated.

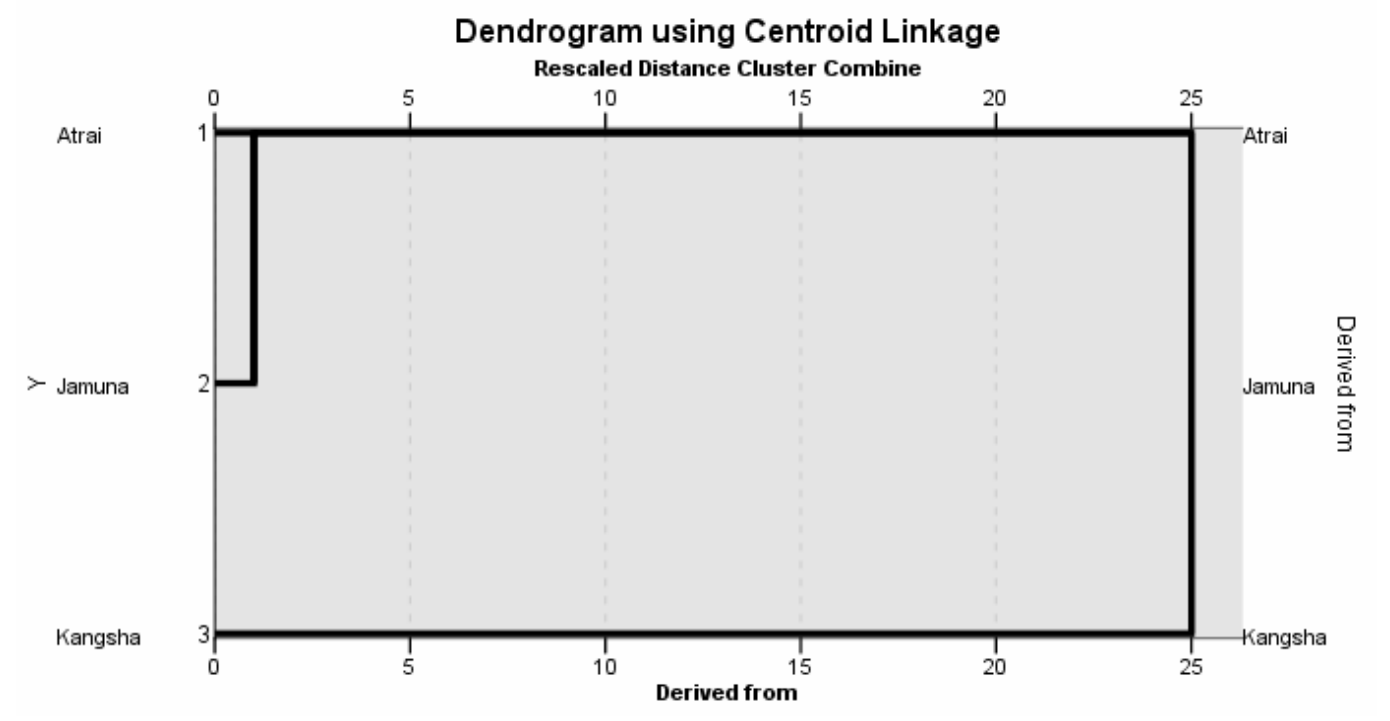

Fig. 05. Dendrogram based on morphometric characters and landmark distances of three Stocks

\section{Discussion}

In the present study, meristic counts of all samples were fairly similar with the findings of Reed et. al., (1967), Hossain et. al., (2015) and Holden and Reed (1972). Among the 3 stocks, the mean number of dorsal fin rays and pectoral fin rays were significantly different $(\mathrm{p}<0.05)$. Nakamura, (2003) also found similar differences in meristic counts in Japanese charr (Salvelinus leucomaenis) among the two river systems, Naka river and Tone river in central Japan and among the tributaries of the Naka River (Ashinagasawa, Akasawa, Ushirosawa and Moto-Okashirasawa streams). In the present study, highly significant morphometric differences were found among the Atrai, Jamuna and Kangsha river's $L$. ariza populations. Among the 10 morphometric measurements, all were highly and significantly different $(p<0.001)$ among the three river stocks. These phenotypic differences among three stocks (the Atrai, Jamuna and Kangsha) may be occurred due to their separate geographical location, different feeding habit, existing environmental variation of their three habitats or may be originated from different ancestors as well as genetic variation. Morphological characters of fish can show high malleability in response to changes in environmental conditions, such as food abundance and temperature (Swain et al., 1991; Allendorf and Phelps, 1980). Generally, fish show greater variances in morphological characters both within and between populations than any other vertebrates and are more vulnerable to environmentally induced morphological variations (Wimberger, 1992). Each of the rivers (the Atrai, Jamuna and Kangsha) of this research work possesses a separate environmental condition from each other. This may be a main cause for the variation among the morphometry of the fishes. Truss network systems are a powerful tool for identifying different stocks of fish species and this method can detect very smallest changes in morphology (Turan et. al., 2004). In the present study, all 22 truss distance (dist 1-2, dist 2-3, dist 3-4, dist 4-5, dist 5-6, dist 6-7, dist 7-8, dist 8-9, dist 910 , dist $1-10$, dist $2-10$, dist $3-10$, dist $1-9$, dist $2-9$, dist 3-9, dist 4-9, dist 2-8, dist 3-8, dist 4-8, dist 5-8, dist 4-7, dist 5-7) were significantly different among the stocks $(\mathrm{p}<0.001)$. Hossain et al., (2010) observed significant differences $(\mathrm{p}<0.05$ or $<0.001)$ in 4 (highest body depth (HBD), pre-orbital length (PrOL), peduncle length (PL) and maxillary barbel length (MxBL)) of 9 morphometric and four of 22 truss network measurements in kalibaus (Labeo calbasu) populations collected from the Jamuna, the Halda and a hatchery in Bangladesh. On the other hand, Rahman et al. (2014) found all morphometric and truss (16 morphometric and 23 truss) measurement significantly different $(\mathrm{p}<0.001)$ in the Old Brahmaputra river, the Tanguar haor and a hatchery in Mymensingh. The significant differences $(\mathrm{p}<0.05)$ were also found in 16 of 25 truss measurements in Anchovy (Engraulisen crasicolus L.) in Black, Aegean and Northeastern Mediterranean sea (Turan et al., 2004). Parvej et al. (2014) found significant differences ( $\mathrm{p}<0.001)$ in 4 of 17 morphometric traits and only 1 of 22 truss network measurements in Eutropiichthys vacha populations from Kaptai Lake, Meghna River \& Tanguar Haor in Bangladesh. In the present experiment, discriminant function (DF) analysis determined the dissimilarity among three stocks and significant correlations were observed between size and truss measurement 
characteristics among three stocks of $L$. ariza. From the discriminant function analysis it was obvious that the 2nd DF explained much less of the variance than did the 1st and therefore much less informative in explaining differences among the stocks. The dendrogram appointed in this study resulted in 2 clusters. The Atrai River and Jamuna river stocks in one cluster and Kangsha river stock in another cluster. The differences between stocks may have been due to variations of environmental, geographical, feeding and genetic as well. Plotting DFs revealed high isolation in morphometrics among the three stocks which was similar to the result of Hossain et al., (2010). The Atrai, Jamuna and the Kangsha stocks were clearly differed by DF analysis based on the morphometric and truss measurements which was also similar to the result of Hossain et al., (2010). The dendrogram employed by Hossain et al., (2010) in his study resulted in 2 clusters: the Jamuna and hatchery stocks of $L$. calbasu in one and the Halda stock of $L$. calbasu in another and this result is similar to the present experiment. They concluded that the morphological difference between the hatchery and wild stocks were possibly due to environmental condition, separate habitat as well as genetic variations. A dendrogram based on data of the meristic and morphometric characters shown that the population of bele, Glossogobius guiris of the pond in Mymensingh region was separated from haor and estuary stocks might be due to environmental factors or separate habitat as well as genetic variability among the stocks reported by Mollah et al., (2012). Likely, in their study, DFs had shown isolation in morphology among the stocks of different sources of Bele, G. guiris.

\section{Conclusion}

There is an apparent decline of L. ariza from the wild sources in Bangladesh from last few years. Landmarkbased morphometric and meristic variations of $L$. ariza collected from three different stocks showed significant differences in all morphometric, meristic and truss network measurements. Furthermore, the plotted DF too showed a significant morphological isolation among the stocks. Relevant information and research of stock structure are crucial for balanced exploitation, selection and breeding, habitat restoration, management and conservation of any species. The baseline data derived from the present study would be useful for the conservation of the reducing stocks of the $L$. ariza and in designing breeding strategies. More research especially on genetic studies and investigations of the impacts of environmental factors is needed for conservation and mass seed production of selected stocks to pave the way to saving this endangered species from extinction in Bangladesh.

\section{Acknowledgement}

The authors take the privilege to acknowledge MOST (Ministry of Science \& Technology, Bangladesh) authorities for providing financial assistance and support.

\section{Conflict of interest}

There was no conflict of interest with anybody or organization.

\section{References}

Ahammad, A.K.S., Haque, M.M., Rahman, A.M., Asaduzzaman, M. 2015.Morpho-genetic Analysis of Three River Populations of Bhagna, Labeo ariza (Hamilton 1807) in Bangladesh. J Aquac Mar Biol, V. 2(3): P. 00029.

Akhteruzzaman, M., Kohinoor, A. H. M., Rajts, F., Khan, A. M., \& Arief, K. H. 1998.Studies on the production performances of small indigenous fish species in Bangladesh. In Proceedings of National Workshop on Food-Based Strategies for Improving Nutrition in Bangladesh, P. 17-28.

Allendorf, F. W. \& Phelps, S. R. 1980.Loss of genetic variation in a hatchery stock of cutthroat trout. Transactions of the American Fisheries Society, V. 109(5): P.537-543.

Bronte C.R., Fleischer G.W., Maistrenko S.G., Pronin N.M. 1999. Stock structure of Lake Baikal omul as determined by whole body morphology. Journal of Fish Biology, V.54: P.787-798.

Creech, S. 1992. A multivariate morphometric investigation of Atherinaboyeri risso, 1810 and A. presbyter cuvier, 1829 (Teleostei: Atherinidae): morphometric evidence in support of the two species Journal of Fish Biology, V. 41: P. 341353.

Dahanukar, N. 2010.Bangana ariza. The IUCN Red List of Threatened Species 2010: http://dx.doi.org/10.2305/IUCN.UK. 20104. RLTS.T166488A6219934.en. Access date: 01 October 2017.

Elliott, N. G. Haskard, K., \& Koslow, J. A. 1995. Morphometric analysis of orange roughy (Hoplostethus atlanticus) off the continental slope of southern Australia. Journal of Fish Biology, V. 46(2): P. 202-220.

Felts, RA., Rajits F, Akhteruzzaman, M. 1996.Small indigenous fish species culture in Bangladesh. IFADEP Technical Brief, Dhaka, Bangladesh, P. 41.

Hockaday, S., Beddow, T.A., Stone, M., Hancock, P., Ross, L.G. 2000. Using truss networks to estimate the biomass of Oreochromis niloticus and to investigate shape characters. Journal of Fish Biology, V.57: P. 981-1000.

Hogan, CM. 2012.Indus River. In: Saundry, P., \& Cleveland, C (Eds.), Encyclopedia of Earth. National Council for Science and the Environment. Washington DC, USA.

Holden, M. \& Reed, W. 1972.West African freshwater fish. Longman Group Ltd., London.

Hossain, M. A., Nahiduzzaman, M., Saha, D., Khanam, M. U. H., \&Alam, M. S. (2010). Landmark-based morphometric and meristic variations of the endangered Carp, Kalibaus, Labeo calbasu, from stocks of two isolated rivers, the Jamuna and Halda, and a hatchery. Zoological Studies, V. 49(4): P. 556-563.

Hossain, M.B., Bhowmik, S., Majumdar, P.R., Saha, P., Islam, M.R.U. 2015. Landmark-Based Morphometric and Meristic Variations in Populations of Mullet, (Rhinomugil corsula) (Hamilton, 1822) in Bangladesh. World Journal of Fish and Marine Sciences. V. 7(1): P. 12-20, 2015.

Hussain, MG., Mazid, MA. 2001. Genetic improvement and conservation of carp species in Bangladesh. BFRI \& ICLARM annual report, Mymensingh, Bangladesh, P. 74.

Jhingran, VG. 1991. Fish \& Fisheries of India. $\left(3 \mathrm{rd} \mathrm{ed}^{\mathrm{n}}\right)$, Hindustan Publishing Corporation, Delhi, India, P. 727.

Kohinoor, A.H.M., Islam, M.L., Wahab, M.A., Thilsted, S.H. 1998. Effect of mola (Amblypharyngodon mola Ham.) on the growth and production of carps in polyculture. Bangladesh Journal of Fish Research, V. 2(2): P.119-126.

Mamuris, Z., Apostolidis, A.P., Panagiotaki, P., Theodorou, A.J., Triantaphllidis, C. 1998. Morphological variation between red mullet populations in Greece. J. Fish Biol. 52: 107-117.

Mollah, M.F.A., S. Yeasmine, M.B. Hossen and A.K.S. Ahammad. 2012. Landmark-based morphometric and meristic variations of Glossogobius giuris in three stocks, Journal of Bangladesh Agricultural University,10, 2, 375-384. 


\section{Ahammad et al.}

Nakamura, T. 2003. Meristic and morphometric variations in fluvial Japanese charr between river systems and among tributaries of a river system. Environmental Biology of Fishes, 66(2), 133-144.

Naser, M. Niamul, 2015. Labeo ariza. In: IUCN Bangladesh. Red List of Bangladesh Volume 5: Freshwater Fishes. IUCN, International Union for Conservation of Nature, Bangladesh Country Office, Dhaka, Bangladesh, P. 101

Parvej, M. R., Islam, M. R., Minar, M. H., Hossain, M. B., \& Tushar, M. R. 2014.Landmark-Based Morphometric and meristic Variations of the Critically Endangered Catfish, Eutropiichthys vacha from Three Different Populations in Bangladesh. World Journal of Fish and Marine Sciences, V. 6(4): P. 378-385.

Rahman, AKA. 2005. Freshwater Fishes of Bangladesh (2nd ed ${ }^{\mathrm{n}}$ ), Zoological Society of Bangladesh, Department of Zoology, University of Dhaka, Bangladesh, P. 394.

Rahman, M. A., Zaher, M., \& Azimuddin, K. M. 2009. Development of fingerling production techniques in nursery ponds for the critically endangered reba carp, Cirrhinus ariza (Hamilton, 1807). Turkish Journal of Fisheries and Aquatic Sciences, V. 9(2).

Rahman, M. M., Sharker, M. R., Sumi, K. R., Alam, M. A., \& Hossen, M. S. 2014. Landmark-based morphometric and meristic variations of stinging catfish, Heteropneustes fossilis (Bloch) among three isolated stocks, the Old Brahmaputra river and the Tanguarhaor and a hatchery. International Journal of Fisheries and Aquatic Studies, V. 1: P.163-170.

Reed, W., J. Burchard, A.J. Hopson, J. Jenness and Yaro, 1967.Fish and Fisheries of Northern Nigeria. Ministry of Agriculture, Northern Nigeria, P. 226
Roberts, T.R. 1997. Systematic revision of the tropical Asian labeo in cyprinid fish genus Cirrhinus, with descriptions of new species and biological observations on C. lobatus. Nat Hist Bull Siam Soc V. 45(2): P. 171-203.

Swain, D. P., Riddell, B. E., \& Murray, C. B. 1991. Morphological differences between hatchery and wild populations of coho salmon (Oncorhynchus kisutch): environmental versus genetic origin. Canadian Journal of Fisheries and Aquatic Sciences, V. 48(9): P. 1783-1791.

Talwar, P. K., \& Jhingran, A. G. 1991.Inland fisheries of India and adjacent countries, Vol. 2.

Turan, C., Erguden, D., Gurlek, M., Basusta, N. \& Turan, F. 2004. Morphometric structuring of the anchovy (Engrulis encrasicolas L.) in the Black, Aegean and Northeastern Mediterranean Seas. Turkish journal of veterinary and animal sciences, V. 28(5): P.865-871.

Turan, C., Oral, M., Ozturk, B. \& Duzgunes, E. 2006.Morphometric and meristic variation between stocks of Bluefish (Pomatomus saltatrix) in the Black, Marmara, Aegean and northeastern Mediterranean Seas. Fisheries Research, V. 79(1): P.139-147.

Vishalakshi, C., \& Singh, B. N. 2008.Differences in morphological traits between two sibling species, Drosophila ananassae and D. pallidosa. Zool Stud, V. 47(3): P. 352-359.

Walter R (1994). Inland fishes of India and adjacent countries. Reviews in Fish Biology and Fisheries V. 4(1): P.135-136.

Wimberger, P. H. (1992). Plasticity of fish body shape. The effects of diet, development, family and age in two species of Geophagus (Pisces: Cichlidae). Biological Journal of the Linnean Society, V. 45(3), P.197-218. 